\title{
Pore size distribution of Brasilia tropical soil in 3 different initial states
}

\author{
Camilla Rodrigues Borges ${ }^{1, *}$, Bruna de Carvalho Faria Lima Lopes ${ }^{2}$, and Manoel Porfírio Cordão Neto ${ }^{3}$ \\ ${ }^{1}$ Federal Institute of Goiás - IFG, Luziânia, Brazil \\ ${ }^{2}$ University of Strathclyde, Civil and Environmental Engineering Department, Glasgow, UK \\ ${ }^{3}$ University of Brasília - UnB, Brasília, Brazil
}

\begin{abstract}
In the last decades there was an evolution in the analysis of the soil structure, most importantly, there was an improvement in the evaluation and in the ways of determining the mentioned structure and how it relates to the hydro-mechanical behaviour of soils. Due to the necessity of understanding the behaviour of tropical soils under different structures (natural, compacted and slurry) this study was developed by means of the Mercury Intrusion Porosimetry (MIP), enabling the analysis of the structural characteristics of these samples. The main objective of this work is to evaluate how the different structures are affected by external loading and how the changes in the pore sizes influences the hydro-mechanical behaviour of the soil in both, saturated and unsaturated conditions. It has been observed that the results regarding the influence of the structure showed a bimodal behaviour. The structural modification of the soil under study, due to the mechanical and / or hydraulic loading, leads to changes in the structure of the macropores and does not affect the micropores. With this, it is noticed that even fixing the parameters related to the microstructure it is possible to make a good adjustment of the macro. This is justified by the fact that the microstructure of all samples are very similar.
\end{abstract}

\section{Introduction}

The future of engineering practice is to incorporate aspects of the microstructure into the macroscopic characteristics of soils in order to simplify and make the geotechnical analysis more realistic. Therefore, it is fundamentally important to understand the structure of soils in its various states (undisturbed, reconstituted, remoulded, compacted) and correlate them, as it is already known that the initial state of the soil dictates its behaviour [1].

Considering the soil as a multiphase porous medium, the variations that occur in any of the phases affect directly the others, influencing the hydraulic and mechanical behaviour of the soil. Deformations in the solid skeleton cause water flow, and the flow of water can cause deformation in the solid skeleton [2,3].

Thus, the hydro-mechanical behaviour of the soil is intrinsically related to the soil structure. Not surprisingly, in recent years there has been an increase in interest concerning soil structure, its evaluation and the aspects of determination of this structure $[2,3]$.

Despite advances achieved over the years regarding soil structure, a very small fraction of the studies published internationally involves tropical soils. Therefore, to fill this gap, this study investigates the structure of Brasilia (Brazil) tropical soil at different states (undisturbed, compacted and slurry), by means of the Mercury Intrusion Porosimetry (MIP) tests. The main aim of this paper is to evaluate how these diverse structures are affected by external loading.

\section{Background}

There are several techniques used for the microstructural analysis of the soil, among them are: particle size distribution, soil water retention curve, reflectometry (optical and time domain), infrared measurements, tomography, microstructural intrusion, Environmental Scanning Electron Microscopy (ESEM) and Mercury Intrusion Porosimetry (MIP).

Amongst the techniques used to investigate the soil microstructure, the Mercury Intrusion Porosimetry test is one of the most used. According to Zhang et al. [4], the MIP test is widely used because of its easy execution. Thus, the technique of Mercury Intrusion Porosimetry is widely recognised as an experimental technique in determining the distribution and structure of porous soils [5-15].

The results obtained from this technique of soil microstructure analysis also allow a better understanding of the soil's mechanical behaviour, since it separates the response of the micro and macrostructure $[16,17]$.

According to Simms \& Yanful [18], the major sources of error of the MIP technique are: (1) the effects of sample preparation to remove water; (2) the effect of pressure generated during MIP on soil structure; and (3) the influence of pore accessibility on the generated PSD.

Despite these limitations, several authors have used the MIP results to predict soil water retention curve

\footnotetext{
${ }^{*}$ Corresponding author: camilla.borges@ifg.edu.br
} 
properties [19-23], as well as macroscopic volume changes, due to the effects of stress paths $[5,6,18,24$ 30].

The soil structure information can be obtained by analysing the pore size density (PSD) curve. According to Romero \& Simms [11], macroscopic properties, such as permeability and soil retention properties, were indirectly obtained through correlations with the PSD in geotechnical applications as an essential element of the soil fabric. In addition, Vazquez et al. [31] assert that the PSD can be seen as a unique statistical distribution, thus able to characterize the soil sample structure.

In general, the pore size distribution in unsaturated soils is often bimodal, comprising: the microstructure associated with the distribution of small intra-aggregate voids, that is, within aggregations of particles, and a macrostructure associated with larger spaces interaggregates, that is between aggregates [32, 33, 7].

Studies such as Simms \& Yanful [22], Romero et al. [27] and Buenfil [10] show that the results of the microstructural pore size distribution with loading paths confirm the microstructure definition proposed by Romero \& Vaunat [34], in which the microstructure is the part of the soil not affected by loading paths.

Mascarenha [12] discussed the effects of loading on collapsed samples and stated that up until the stress level studied, the changes in porosity arise from the variation of the macropores, while the micropores remain intact, even in samples that have collapsed. The author shows that in the relationship between the PSD and the pore diameter for natural and collapsed samples, there were few alterations in the soil structure after collapse, with only a decrease in the pore density in the macrostructure, with a small variation in the value of the dominant pores diameters. The microstructure (micropores) of the soil remained constant in all three cases.

\section{Methodology}

The material chosen for this experimental research was the residual weathered soil collected in the experimental area at University of Brasilia. This choice is due to the fact that this soil, namely Brasilia soil, has been studied for several years and therefore it is well known and characterised. Some of the characteristics of the Brasilia soil includes: liquid limit, $\mathrm{w}_{\mathrm{L}}$, of $42 \%$, plasticity limit, $\mathrm{w}_{\mathrm{P}}$, of $24 \%$, and unit weight of $26.87 \mathrm{kN} / \mathrm{m}^{3}$. These values are commonly for soils around this region.

According to Camapum de Carvalho et al. [35] this first layer of lateritic residual soil has a very porous structure, is unsaturated and with low bearing capacity. This structure promotes the formation of bundles of clays, giving to these soils, despite the clay matrix, hydraulic behaviour similar to that of fine granular soils.

In tropical climate soils, particles are usually aggregated. The porous clay of Brasilia has striking features, such as the presence of aluminium and iron oxide, which is the reason for the aggregations that characterise the material. These aggregations give the soil a bimodal structure, which can be observed on its soil water retention curve and pore size distribution curve. In order to understand how the Brasilia soil responds in terms of its structure to external loading, the following experimental programme was developed.

Samples were prepared in three states, which are herein called Natural (N), Compacted (C), and Slurry (S). The natural samples are essentially undisturbed samples.

The method of preparation of the compacted samples was carried out with the objective of developing samples with as minimum as possible variability of physical properties, that is to say, there is a uniformity of particle size and void ratio among the compacted samples. To achied this, samples underwent air drying until hygroscopic moisture was reached, then they were sieved (2.0 mm sieve). The compacted samples presented on this paper are below the optimal normal proctor energy and moisture conditions, on the dry side of optimum $(\mathrm{w}=20 \%$ and $\gamma_{\mathrm{d}}=13.5 \mathrm{kN} / \mathrm{m}^{3}$ ). They have been compacted semistatically keeping the density, the established moisture and the calculated void ratio constants $(\mathrm{e}=1.20)$. This choice is justified by the fact that compacted samples produced on the dry of optimum have an open structure.

The objective of the process of preparation of the soil samples from the slurry state was to produce samples in a condition in which the original structure was completely erased and consequently presented high void ratio values.

Initially, the soil was air dried and then sieved in the $2.0 \mathrm{~mm}$ sieve. Samples were wetted to reach the moisture content of $63 \%$, corresponding to 1.5 times the liquid limit of the material, obtaining the consistency of a slurry. These samples were homogenized with the aid of a mechanical mixer for 15 minutes and allowed to stand until they began to dry. Just before cracking appeared on the soil surface, they were moulded.

Then, all samples underwent consolidation under saturated and unsaturated conditions. The conventional one-dimensional apparatus was used for carrying out the saturated tests. For the preparation of saturated samples, soil samples were moulded into a steel ring, placed in the cell and saturated. After saturation, vertical load increments were performed.

As for the tests in the unsaturated condition, a cell with a suction-displacement axis control was used. For the preparation of the unsaturated samples, soil samples were moulded in a steel ring and placed on top of a porous stone for its saturation. After saturation, samples were installed in the chamber on top of the porous stone with high air inlet value. Samples were subjected to $1000 \mathrm{kPa}$ suction and, after stabilization, vertical load increments were performed hydraulically.

After reaching the targeted loading stage, specimens of $1 \mathrm{~cm}^{3}$ were moulded and water was extracted from the specimen through the lyophilisation process, to restrict structural changes as suggested by Delage \& Pellerin [36].

The sample's structure was assessed by means of Mercury Intrusion Porosimetry (MIP). This tests were carried out on specimens with different void ratios following saturated and unsaturated loading paths. This procedure is intended to obtain information that helps to understand how the loading affects the distribution of pores. Due to size restrictions, only results obtained from eight samples are presented here, as shown in Table 1. 
Table 1. Characteristics of samples

\begin{tabular}{cccccccccc}
\hline \multirow{2}{*}{ State } & Sample & $\gamma_{\mathrm{d}}\left(\mathrm{kN} / \mathrm{m}^{3}\right)$ & $\mathrm{W}(\%)$ & $\mathrm{e}_{\mathrm{i}}{ }^{1}$ & $\mathrm{e}_{\mathrm{nw}}{ }^{2}$ & $\%=\frac{e_{i}^{1}-e_{n w}}{e_{i}^{1}}$ & Loading (kPa) & Suction (kPa) \\
& $\mathrm{N}-0-0$ & 9.91 & 13.02 & 1.69 & 1.502 & $+11 \%$ & 0 & 0 \\
\multirow{2}{*}{ Natural } & $\mathrm{N}-800-0$ & 14.13 & 27.64 & 0.9 & 0.818 & $+9 \%$ & 800 & 0 \\
& $\mathrm{C}-0-0$ & 12.21 & 20.00 & 1.22 & 1.052 & $+14 \%$ & 0 & 0 \\
\multirow{3}{*}{ Compacted } & $\mathrm{C}-800-0$ & 15.21 & 28.18 & 0.77 & 0.812 & $-10 \%$ & 800 & 0 \\
& $\mathrm{C}-800-1000$ & 14.62 & 13.19 & 0.84 & 0.822 & $-2 \%$ & 800 & 1000 \\
\hline \multirow{3}{*}{ Slurry } & $\mathrm{S}-0-0$ & 12.66 & 44.58 & 1.14 & 0.967 & $+14 \%$ & 0 & 0 \\
& $\mathrm{~S}-800-0$ & 15.6 & 26.24 & 0.68 & 0.661 & $+4 \%$ & 800 & 0 \\
& $\mathrm{~S}-800-1000$ & 16.18 & 21.54 & 0.66 & 0.566 & $-1 \%$ & 800 & 1000 \\
\hline
\end{tabular}

${ }^{1}$ Measured void ratio of sample, ${ }^{2}$ Void ratio of samples obtained by MIP

\section{Results and discussions}

Fig. 1 shows the experimental results of the cumulative curves obtained through the MIP tests performed on all samples presented in this paper. The MIP test works by pushing the mercury to fill the voids within the sample. The pressure applied by the equipment to push mercury inside of the voids is related to the size of the pore. The higher is the pressure required the lower is the size of the pores. The equipment has a maximum pressure limitation, which means that at some point, smaller voids will not be filled. In order to analyse the relationship between the measured void ratio $\left(\mathrm{e}_{\mathrm{i}}\right)$ of the specimen at a macro scale and the void ratio generated by mercury filling the pores of specimens in the MIP test $\left(\mathrm{e}_{\mathrm{nw}}\right)$, the error between these void ratios (\%) was calculated (Table 1$)$.

In addition to the effects associated with the limitations of the MIP test, this difference between the void ratios is associated with two other effects. The first is related to pores within clay aggregates that were not connected to larger pores and thus were isolated within the sample. The other effect is associated with sample preparation, although the lyophilisation process reduces the changes caused on soil structure by the water removal process, it does not eliminate it. Several authors, including Romero \& Simms [11], have reported that the void ratio of a sample obtained by the MIP $\left(\mathrm{e}_{\mathrm{nw}}\right)$ does not coincide with the actual value of void ratio of the sample and that this would be one of the limitations of the technique.

Sasanian \& Newson [37] evaluated the effects of moisture content variations over the pore size distribution of two clays. According to the authors, the two clays have similar results, suggesting that the error may be inherent to the test and independent of the clay type.

Due to the difficulty of analysing only qualitatively the loading effects on the pore size distribution, the cumulative experimental curves have been fitted using the equation proposed by Durner [38], which is a modification of the van Genutchen equation [39]. This modified equation includes multi modes, allowing the separation and capture of the micro and macro components of the soil structure, such analysis have been successfully performed by Lopes et al. [40]. For this case the equation of the void ratio intruded by mercury $\left(\mathrm{e}^{*}{ }_{\mathrm{nw}}\right)$ adjusted can be presented as:

$$
e_{n w}^{*}=e_{m}\left[\frac{1}{1+\left(\alpha_{m} D\right)^{n_{m}}}\right]^{\left(1-\frac{1}{n_{m}}\right)}+e_{M}\left[\frac{1}{1+\left(\alpha_{M} D\right)^{n_{M}}}\right]^{\left(1-\frac{1}{n_{M}}\right)}
$$

where, subscript $m$ is associated with the micropores, and $M$ to the macropores, $e_{m}$ and $e_{M}$ are the void ratios, $\alpha_{m}$ and $\alpha_{M}$ are fitting parameters related to a dominant pore size; and $\mathrm{n}_{m}$ and $\mathrm{n}_{M}$ are fitting parameters associated with the uniformity of pore size.

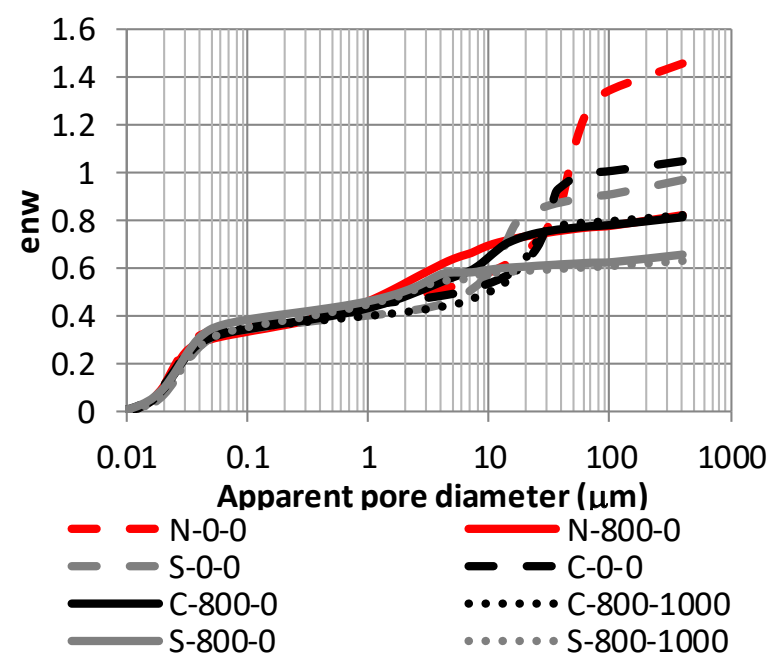

Fig. 1. Experimental cumulative intrusion curves of all samples

One of the hypotheses assumed was that the microstructure does not change, or at least the variation is very small, which is supported by additional analysis carried out by Borges [41]. Thus, in all fittings presented here the parameter related to the microstructure, $\left(\mathrm{e}_{\mathrm{n}}, \alpha_{\mathrm{m}}\right.$, and $\mathrm{n}_{\mathrm{m}}$ ) were kept constant and equal for all samples. To determine the value of the fixed parameters of the micropores presented here, the average of values $\left(\mathrm{e}_{\mathrm{n}}, \alpha_{\mathrm{m}}\right.$, and $\mathrm{n}_{\mathrm{m}}$ ) found in the fittings where all parameters of the micro and macropores were allowed to change was taken. With the microstructure parameters fixed, the parameters related to macropores $\left(e_{M}, \alpha_{M}\right.$, and $\left.n_{M}\right)$ were adjusted.

Table 2 presents the macrostructure fitting parameters for the samples. In general, the macropore parameters evolve as expected. The decrease in $\alpha_{M}$ values is higher for the natural sample than for the compacted and slurry samples at the same state, which may be related to the existence of a weak bond between aggregates (probably 
iron oxide) that are not present in the other samples (Fig. 2).

Table 2. Macro parameters for PSD fitting, when micro parameters are fixed $\mathrm{e}_{\mathrm{m}}=0.34, \alpha_{\mathrm{m}}=0.029$ and $\mathrm{n}_{\mathrm{m}}=4.65$

\begin{tabular}{|c|c|c|c|c|}
\hline \multirow{2}{*}{ Samples } & \multicolumn{3}{|c|}{ Macro parameters } & \multirow{2}{*}{$\mathrm{R}^{2}$} \\
\hline & $\mathrm{e}_{\mathrm{M}}$ & $\alpha_{M}$ & $\mathrm{n}_{\mathrm{M}}$ & \\
\hline $\mathrm{N}-0-0$ & 1.11 & 87.02 & 1.67 & 0.978 \\
\hline $\mathrm{N}-800-0$ & 0.48 & 12.05 & 1.56 & 0.999 \\
\hline $\mathrm{C}-0-0$ & 0.71 & 50.52 & 1.61 & 0.975 \\
\hline C- $800-0$ & 0.47 & 16.30 & 1.59 & 0.998 \\
\hline C- $800-1000$ & 0.48 & 27.80 & 1.78 & 0.991 \\
\hline S-0-0 & 0.63 & 22.18 & 1.92 & 0.992 \\
\hline S-800-0 & 0.39 & 8.05 & 1.33 & 0.996 \\
\hline S- $800-1000$ & 0.29 & 6.70 & 1.54 & 0.995 \\
\hline
\end{tabular}

After this bond is destroyed by loading, the natural sample behaves similarly to the samples in the other states (Figure 2). Although the initial structures are different, the values of $\alpha_{M}$ decrease, which means that all the samples would evolve to a unimodal behaviour if the vertical loads continued to increase.
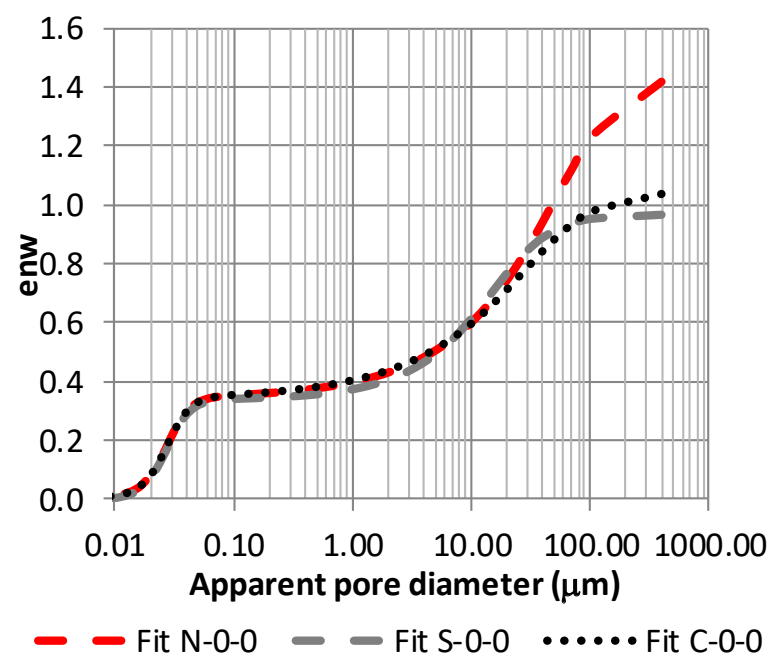

Fig. 2. Fitting curves of cumulative intrusion curves for natural, compacted and slurry saturated samples not loaded

For the compacted samples (Fig. 3) the values of $n_{M}$ could mean that loading can lead to a more uniform distribution of the macropores, its value being around 1.5, the small variation can also be a result of the sampling process, that is, statistical phenomenon. If the hypothesis that $n_{M}$ is little influenced by structure, loading and the imposition of suction, it is possible to assume that this parameter is not related to the structure, but with an intrinsic soil property associated with grain size, shape of grains, the interaction between minerals, clay, water, or others.

The results of the soil in the slurry state are shown in Fig. 4, it is possible to observe that there is a decrease of the values of $\alpha_{M}$, indicated in the figure by the different inclination of the curves, note that this does not undergo major changes during loading. On the other hand, the values of $e_{m}$ changes more significantly, which decrease with the application of loading and with the imposition of suction.
All this confirms the analyses carried out by Borges [40] in which it was observed that none of the processes of obtaining the samples (loading, cycles of wetting and drying, compaction and slurry preparation) were able to significantly affect the micropores.

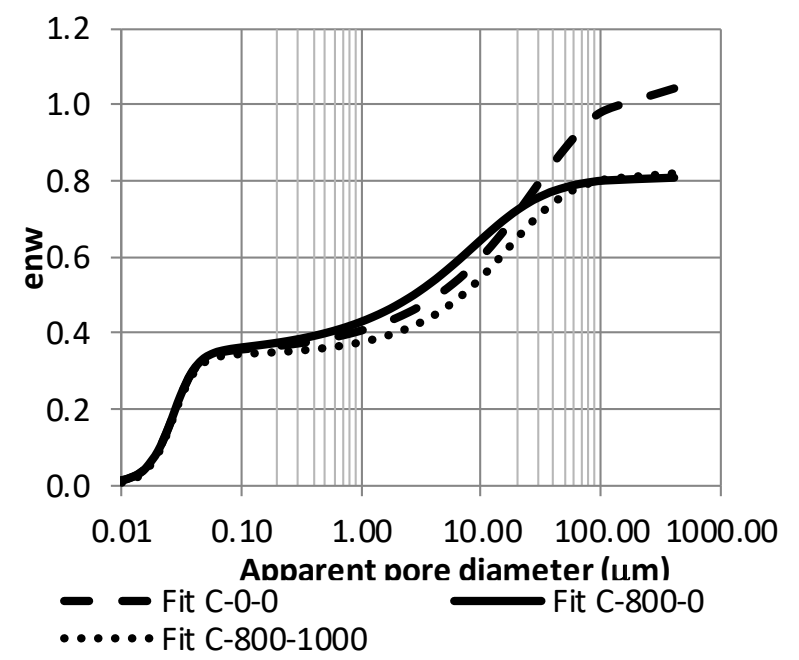

Fig. 3. Fitting curves of cumulative intrusion curves for all three compacted samples

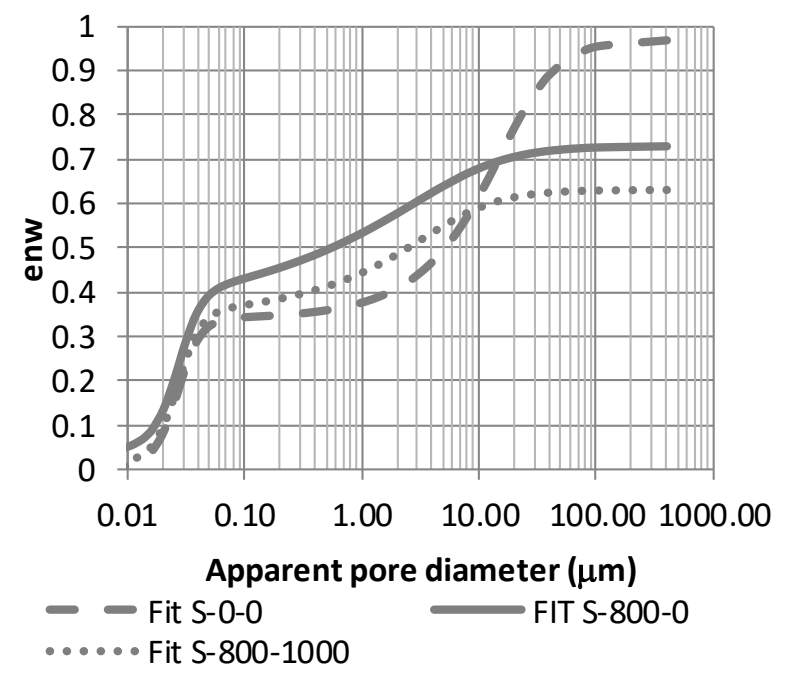

Fig. 4. Fitting curves of cumulative intrusion curves for all three slurry samples

\section{Final remarks}

The work carried out and presented here had its focus on the structural behaviour of the soil in saturated and unsaturated conditions. From the analysis and discussion of the results, some observations and hypotheses, valid within the limits of this study, could be raised.

Regarding the influence of the structure on soil behaviour, it was verified that all the samples presented a bimodal pore size distribution. The segment of the curve associated with the micropores is very similar in the three soil states; this means that the difference in soil structure does not affect the level of micropores. Additionally, the structural modification of the soil under study, due to the mechanical and / or hydraulic loading, leads to changes in 
the structure of the macropores and does not affect the micropores.

Furthermore, it is noted that even keeping the parameters related to the microstructure constant in the adjustment of the macro, the results are good. This is justified by the fact that the microstructure of all samples are very similar.

The authors would like to acknowledge both Brazilian research councils, the National Council for Scientific and Technological Development $(\mathrm{CNPq})$ and the National Council for the Improvement of Higher Education (CAPES) for funding this research.

\section{References}

1. W.D. Carrier, J.F. Beckman. Géotechnique, 35, 2:223229. (1985)

2. M. Sánchez, A. Gens, S. Olivella. Thermo-hydromechanical modelling of low permeability media using a double-porosity formulation. Mecânica Computacional. XXIII, pp. 733-754 (2004)

3. E. Romero, Engineering Geology, 165, 24, (2013)

4. B. Zhang, W.I. Liu, X. Li. Applied Surface Science. 253:1349-1355 (2006)

5. P. Delage, G. Lefebvre. F Geotechnical Journal, 21: 21-35 (1984)

6. F.J. Griffiths, R.C. Joshi. Géotechnique, 39 (1): 159-167. (1989)

7. P. Delage, M. Audiguier, Y.J. Cui, M.D. Howatt. Canadian Geotechnical Journal, 33: 150-158. (1996)

8. D. Penumadu, J. Dean. Canadian Geotechnical Journal, 37: 393-405 (2000)

9. P.H. Simms, E.K. Yanful. Canadian Geotechnical Journal, 38: 741-754 (2001)

10. C.M.B. Buenfil. Caracterización Experimental del Comportamiento Hidromecánico de uma Arcilla Compactada. Thesis, Departamento de Engenharia de Terreno e Cartografia, Universidade Politécnica da Catalunia, Barcelona, 466 p. (2007)

11. E. Romero, P.H. Simms. Geotechnical Geol. Engineering. 26, 6:705-727 (2008)

12. M.M.A. Mascarenha. Influencia da microestrutura no comportamento hidromecânico de uma argila siltoso não saturada incluindo pequenas deformações. Tese de Doutorado, Universidade de Brasília, Brasília, 158p. (2008)

13. A. Koliji, L. Vulliet, L. Laloui. Canadian Geotechnical Journal, 47: 297-311 (2010)

14. V. Sivakumar, R. Sivakumar, J. Boyd, P. Mackinnon. Géotechnique, 60, 8: 581-594 (2010)

15. E.E. Alonso, N.M. Pinyol, A. Gens. Géotechnique, 63, 6: 463-478 (2013)

16. E.E. Alonso, J. Vaunat, A. Gens. Engineering Geology, 54: 173-183 (1999)

17. B. Lloret, N. Khalili. International Journal for Numerical Analytical Methods Geomechanics, 24: 893-927 (2000)

18. P.H. Simms, E.K. Yanful. Géotechnique, 54, 6: 421-426 (2004)

19. S. Prapaharan, A.G. Altschaeffl, B.J. Dempsey. Journal of Geotechnical Engineering, 111, 9: 1139-1143 (1985)
20. E. Romero. Characterisation and Thermo Hydromechanical Behaviour of Unsaturated Boom Clay: An Experimental Study. Thesis, Universidade Politécnica da Catalunia, Barcelona. 405p. (1999)

21. K.K. Aung, H. Rahardjo, E.C. Leong, D.G. Toll. Geotechnical and Geological Engineering, 19: 401-416 (2001)

22. P.H. Simms, E.K. Yanful. Géotechnique, 52, 4: 269-278 (2002)

23. P.H. Simms,E.K. Yanful. Canadian Geotechnical Journal, 42: 499-514 (2005)

24. M. Al-Mukhtar, N. Balanteur, D. Tessier, S.K. Vanapalli. Applied Clay Science. 11:99-115 (1996)

25. Y. Cui, M. Yahia-Aissa, P. Delage. Engineering Geology, 64, 233-250 (2002)

26. O. Cuisinier, L. Laloui. International Journal for Numerical and Analytical Methods in Geomechanics. 28, 6:483-499 (2004)

27. E. Romero, C. Hoffmann, E. Castellanos, J. Suriol, Advances in 157 Understanding Engineered Clay Barriers. 193-202 (2005)

28. A. Koliji, L. Laloui, O. Cuisinier, O., Vulliet, L. Transport in Porous Media, 64 (2): 261-278 (2006)

29. C. Hoffmann, E.E. Alonso, E. Romero. Physics and Chemistry of the Earth, 32: 832-849 (2007)

30. A. Tarantino, E. De Col. Geotechnique, 58: 199-213 (2008)

31. E.V. Vazquez, R.G. Moreno, A.M. Tarquis, A.S. Requejo, J.M. Mirás-Avalos, J. Paz-Ferreiro. Multifractal characterization of pore size distributions measured by mercury intrusion porosimetry. 19th World Congress of Soil Science, Soil Solutions for a Changing World, published on DVD (2010)

32. S. Ahmed, C.W. Lovell, S. Diamond. Journal Geotechnical Engineering Div. GT 4, 407-425(1974)

33. E.E. Alonso, A. Lloret, A. Gens. Proc. 1st Int. Conf. Unsaturated Soils, 1: 11-16 (1995)

34. E. Romero, J. Vaunat. Experimental Evidence and Theoretical Approaches in Unsaturated Soils. 91-106 (2000)

35. J. Camapum de Carvalho; J.J. Crispel; C. Mieussens; \& A. Nardone. La Reconstitution Des Eprouvettes En Laboratoire: Theorie e Pratique Operatoire. RAPPORT DE RECHERCHE, LPC Paris, 145(1): 1-53. (1987).

36. P. Delage, F.M. Pellerin. Clay Miner. 19, 2, 151-160. (1984)

37. S. Sasanian, T. Newson. Engineering Geology, 158: 15-22. (2013)

38. W. Durner. Water Resourses Res., 30: 211-223 (1994).

39. M. van Genutchen. Soil Sci. Soc. Am. J., 44: 892-898 (1980)

40. B.C.F.L. Lopes, A. Tarantino, M.P. Cordão Neto. An approach to detect micro- and macro-porosity from mip data. Unsaturated soils : research \& applications : proceedings of the Sixth International Conference on Unsaturated Soils, UNSAT 2014, 685-690 (2014)

41. C.R. Borges, Estudo microestrutural do comportamento hidromecânico do solo de Brasília-DF, Tese de Doutorado, Universidade de Brasília, Faculdade de Tecnologia. Departamento de Engenharia Civil e Ambiental, xxxii, 112p. (2014) 